\title{
Valve-in-Valve Transcatheter Aortic Valve Implantation of an Evolut $R$ in a Degenerated Lotus Valve
}

\author{
Lars 0 Conzelmann ${ }^{1 *}$, Alexander Würth ${ }^{2}$, Bernd-Dieter Gonska ${ }^{2}$ and Uwe Mehlhorn ${ }^{1}$ \\ ${ }^{1}$ HELIOS Clinic for Cardiac Surgery Karlsruhe, Germany \\ ${ }^{2}$ Medical Clinic III - Department of Cardiology, Sankt Vincentius Hospital Karlsruhe, Germany
}

Submission: July 30, 2019; Published: August 19, 2019

*Corresponding author: Lars Oliver Conzelmann, HELIOS Clinic for Cardiac Surgery, Karlsruhe, Franz Lust Strasse 30 , 78185 Karlsruhe, Germany

\section{Case Report}

Degeneration of bioprosthesis also occurs in transcatheter aortic valve implantation. Treatment option in severe bioprosthetic failure is either surgical aortic valve replacement or transcatheter valve-in-valve implantation. Information about feasibility and outcome of the latter interventions is sparse.

In November 2016, a 79-year old lady received a transfemoral transcatheter aortic valve implantation with a Boston Scientific Lotus valve $(23 \mathrm{~mm})$ suffering from symptomatic aortic stenosis. Intraoperatively, a permanent pacemaker was implanted due to an AV block grade III. A gradient of $27 / 18 \mathrm{mmHg}$ was measured at discharge. Exactly two years later, in November 2018, she represented with severe dyspnea. Echocardiography revealed a degenerated TAVI-bioprosthesis with an orifice area of $0.8 \mathrm{~cm}^{2}$ and a Pmax/mean of $90 / 50 \mathrm{mmHg}$. Due to the restricted condition and comorbidities of this patient (logistic EuroSCORE I $32.75 \%$ ) a valve-in-valve procedure was discussed. Meticulous planning including coronary angiography and CT-scan revealed an inner valve diameter of $18 \mathrm{~mm}$, a height of $20 \mathrm{~mm}$, uncritical coronary anatomy without risk of obstruction and a possible transfemoral approach. After deliberate assessment a Medtronic Evolut R 23mm seemed to fit best in this case. The valve-in-valve procedure was performed under general anesthesia. Predilation with a $20 \mathrm{~mm}$ Balloon was performed for sizing confirmation (Video 1). Thereafter a Medtronic Evolut R 23mm was implanted uneventfully into the Lotus valve (Figure 1 \& Video 2). After implantation the valvular gradient decreased to $0 \mathrm{mmHg}$. Postimplantation angiography showed no aortic regurgitation and instant staining of both coronary arteries (Video 3). The patient was discharged with clear improvement. This is the first case of a successful valve-in-valve of a Medtronic Evolut $\mathrm{R}$ into a degenerated Lotus valve. The procedure can be done safely and easily with a good result.

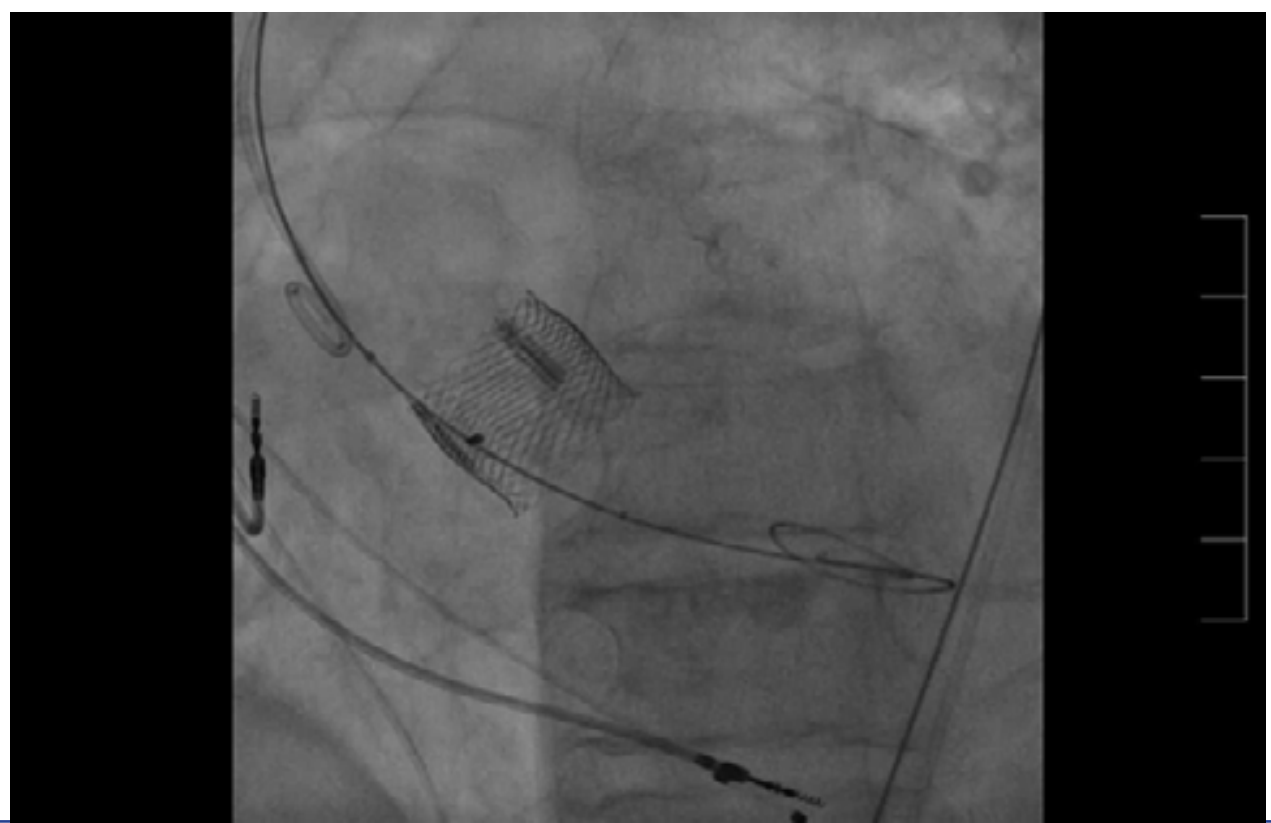




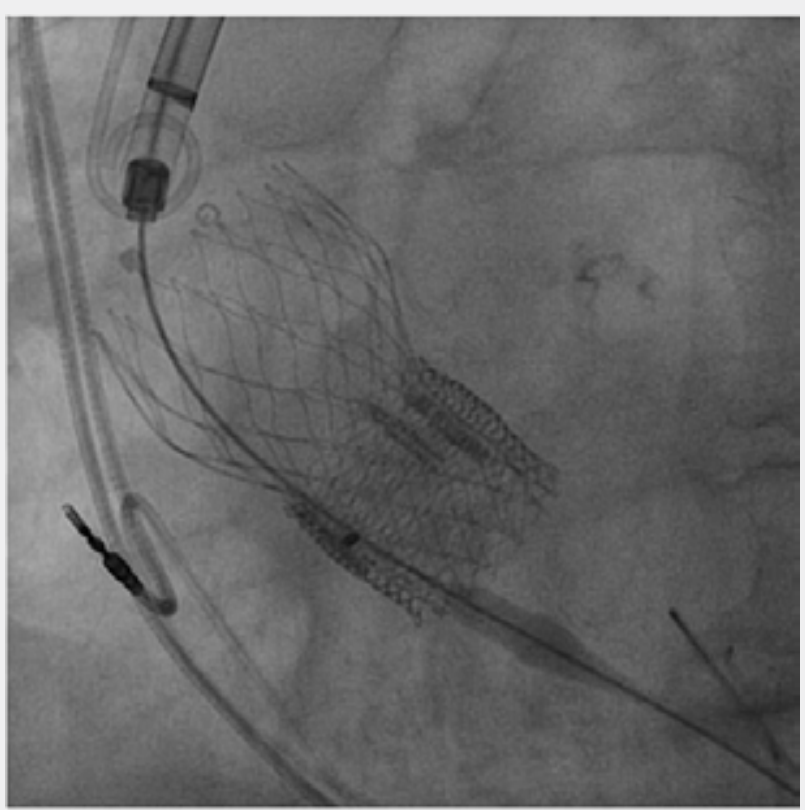

Figure 1:

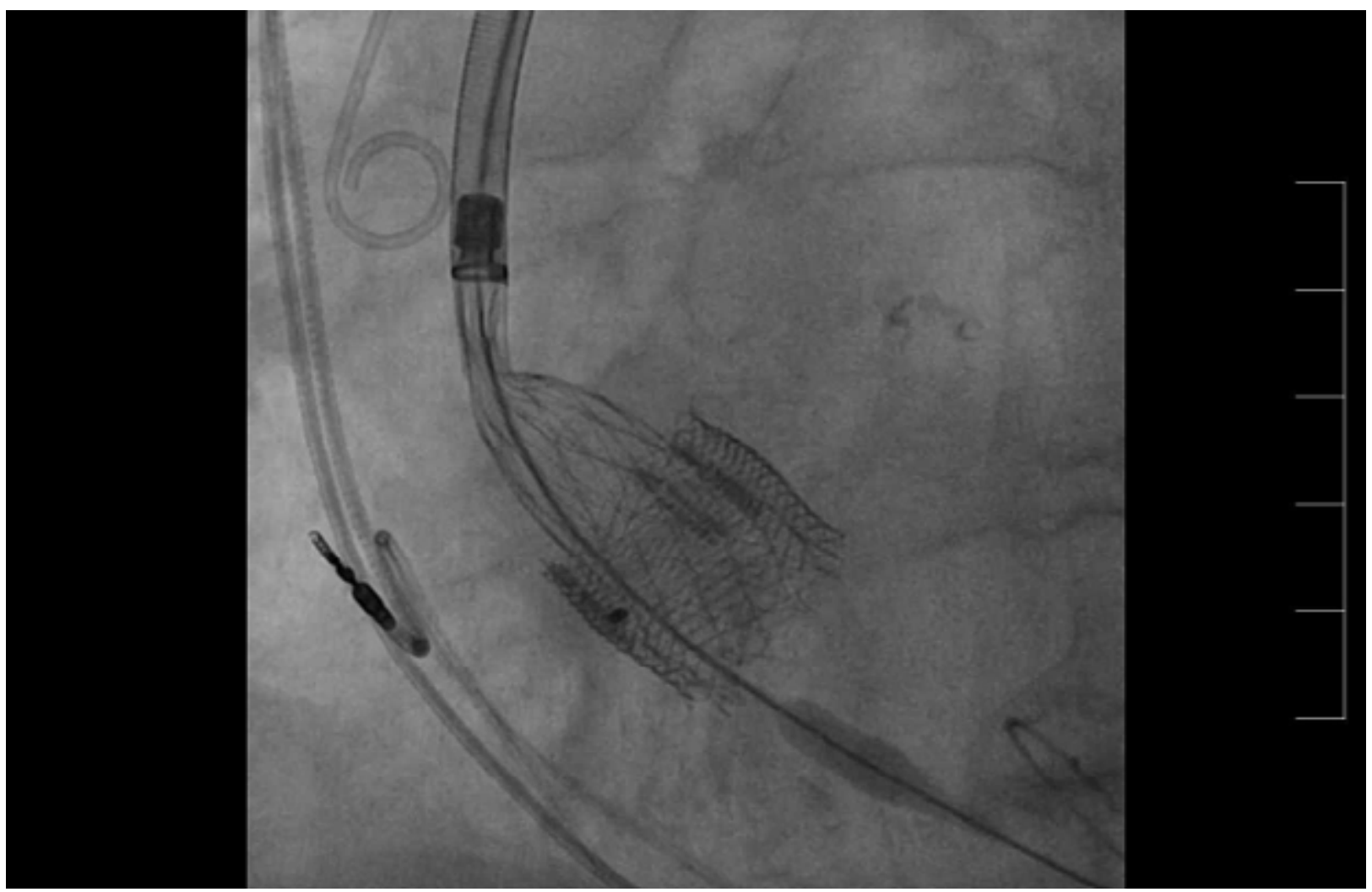




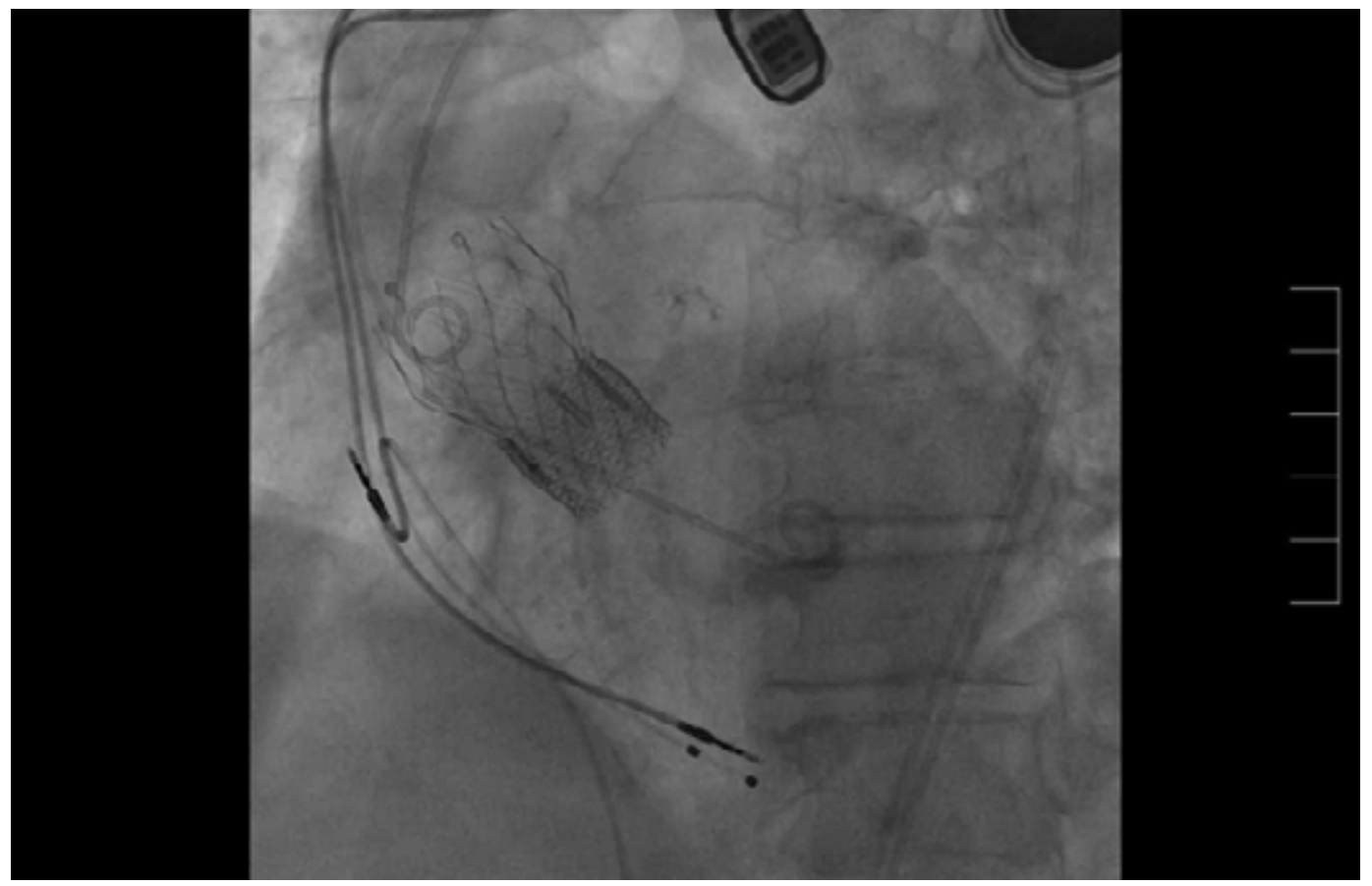

This work is licensed under Creative

Commons Attribution 4.0 License

DOI: 10.19080/JOCCT.2019.14.555893

Your next submission with Juniper Publishers
will reach you the below assets
- Quality Editorial service
- Swift Peer Review
- Reprints availability
- E-prints Service
- Manuscript Podcast for convenient understanding
- Global attainment for your research
- Manuscript accessibility in different formats
( Pdf, E-pub, Full Text, Audio)
- Unceasing customer service
Track the below URL for one-step submission
https://juniperpublishers.com/online-submission.php

